\title{
Lung Cancer Patients Benefit from Second Opinions by Improvement of Diagnosis and Therapy
}

\author{
Romane M Schook ${ }^{1}$, Marleen J ter Avest ${ }^{1}$, Coralien H van Setten ${ }^{1}$, Frances F de Man ${ }^{1}$, Egbert F Smit ${ }^{1}$ \& Pieter E \\ Postmus ${ }^{1}$ \\ ${ }^{1}$ Department of Pulmonary Diseases, VU University Medical Center, Amsterdam, The Netherlands \\ Correspondence: Romane M Schook, Department of Pulmonary Diseases, VU University Medical Center, \\ Amsterdam, The Netherlands. Tel: 31-20-444-2193. E-mail: r.schook@vumc.nl
}

\author{
Received: May 3, 2014 Accepted: May 22, 2014 Online Published: May 27, 2014 \\ doi:10.5539/cco.v3n1p43 URL: http://dx.doi.org/10.5539/cco.v3n1p43
}

\begin{abstract}
Purpose: To collect data from the initial evaluation of patients referred for a second opinion to a specialist pulmonary oncology clinic and compare these with the data of the re-evaluation (second opinion) conducted there to identify discrepancies in diagnosis, stage and therapeutic advice.

Methods: Demographics and disease characteristics of 188 patients referred between January 2005 to December 2009 were collected from medical records, next to therapeutic advice. The data of both initial and second evaluations were compared with each other.

Results: At time of referral, the (clinical/histopathological) diagnosis was known in 174 patients (92.6\%) and the stage in 162 patients $(86.2 \%)$. Forty-eight percent of the patients had received prior therapy and $73 \%$ a therapeutic advice. Next to data review, additional diagnostic procedures were performed in $68 \%$ of the patients. There were discrepancies between the initial and second opinion in diagnosis (17 patients, 9\%), stage (24 patients, 13\%) and therapeutic advice (70 patients, 37\%). The second opinions led to a total of 91 discrepancies, 53 of these had a potential major impact on patient outcomes in terms of survival, morbidity and quality of life. For patients with advanced lung cancer, the results were similar but the number of changed stages, therapeutic advices and discrepancies with a potential impact on patient outcomes were slightly higher $(15 \%, 40 \%$ and $51 \%$ respectively).
\end{abstract}

Conclusions: Lung cancer second opinions referrals led to significant discrepancies in diagnosis and therapeutic advice in a substantial number of patients. This might be translated in better (palliative) care.

Keywords: second opinion, lung cancer, discrepancies, therapeutic advice, patient outcomes

\section{Abbreviations}

NSCLC: Non-Small Cell Lung Cancer

SCLC: Small Cell Lung Cancer

ED: Extensive Disease

CT: Computed Tomography

EGFR: Epithelial Growth Factor Receptor

PET: Positron Emission Tomography

EUS/EBUS: Endoscopic Ultrasound/Endobronchial Ultrasound

\section{Introduction}

Although peer consultation between colleagues account for the majority of second opinion requests in daily oncology practice (Moumjid, Gafni, Bremond \& Carrere, 2007), the phenomenon of patients asking a second opinion is not uncommon, because of the life-threatening character of the disease and potential mutilating and toxic treatment modalities (Mellink et al., 2003). Patients' main reasons to seek a second opinion are the wish for more information about the treatment options, hope for a different advice, confirmation and/or reassurance of the proposed therapeutic management, unfulfilled (information) needs (e.g. about diagnosis, treatment and prognosis) and previous negative experiences with their treating physicians (Mellink et al., 2003; Maaskant, Muilekom van, 
2009; Tattersall et al., 2009). The rapid expansion of information supply and seeking, due to the increasing use of Internet-based information sources and the growing autonomy of patients, has contributed to the increase of patient initiated second opinions (Moumjid et al., 2007; Mellink et al., 2003; Maaskant et al., 2009; Tattersall et al., 2009). According to Hewitt et al., in 1982, already 56\% of 1500 cancer survivors had sought at least one second opinion (Hewitt, Breen, \& Devesa, 1999). Despite evidence of beneficial effects and probable financial advantages, the usefulness and value of patient initiated second opinions are often questioned though (DiPiro, van Sonnenberg, Tumeh, \& Ros, 2002; Epstein, Walsh, \& Sanfilippo, 1996; Postmus, 1998; Wurzer et al., 1998).

Lung cancer is the most important cause of cancer related death among men and women worldwide, accounting for 1.38 million deaths annually. Facing a dismal prognosis and experiencing particularly intense distress as compared to other cancer patients (Ellis, 2012), lung cancer patients are very likely to request a second opinion. However, to the best of our knowledge, there are no reports available on the incidence and/or outcomes of lung cancer patient initiated second opinions. In the view of the current discussion on the usefulness of patient initiated second opinions, the growing wish of patients to do such requests and the expected increase of lung cancer incidence and management related costs, it is important to gain more insight into lung cancer patients initiated second opinions.

In present study, we retrospectively collected data from the initial evaluation of patients visiting a specialist pulmonary oncology clinic for a second opinion and compared these with the data of the re-evaluation conducted there, to identify discrepancies in diagnosis, stage and therapeutic advice.

\section{Methods}

\subsection{Settings}

Generally in the Netherlands, when the diagnosis lung cancer is suspected, for instance after chest X-ray or hemoptysis, patients are usually referred to a team of pulmonologists at a nearby general or university hospital. Additional staging diagnostics are performed there and the diagnosis is usually confirmed. Patients receive a therapeutic advice and therapy usually takes place in the same hospital. Although therapy often involves different disciplines (Pulmonology, Radiotherapy and Thoracic Surgery), the pulmonologist is usually the principal treating physician for patients. The therapeutic advice is formed in consultation with colleagues, in a multidisciplinary team (MDT).

If the diagnostic procedures fail, patients may be referred to a more specialised hospital to complete diagnosis and staging. Patients may also be referred for specific diagnostics or therapies not available in the referring hospital (e.g. EGFR mutation analysis, mediastinoscopy or stereotactic radiotherapy) or for a second opinion. Depending on the outcome of the referring consultation, patients are sent back or choose to stay at the specialist hospital.

The VU University Medical Center (VUmc) is a tertiary specialist pulmonary oncology centre with a specialized MDT of experienced specialists (pulmonologists, radiotherapists and thoracic surgeons), equipped with advanced techniques for diagnosing and staging lung cancer (e.g. PET-CT-scans, mutation analysis facilities). Patients are discussed in the MDT weekly. Around 400 new patients are seen yearly from all over the country (from both urban and rural area), partly second opinions. Patients in this study came from 46 general and 6 university hospitals.

\subsection{Study Population}

In the present study a patient initiated second opinion was defined as a consultation for re-evaluation of the patient's case, at his/her own request with or without the agreement of his/her treating pulmonary specialist. Due to the nature of the second opinions (patient initiated) and their timing (sometimes immediately after the first consultation at the original hospital), this implies that the evaluation in the first hospital was not always complete and subsequently a therapeutic advise had not always been given at time of presentation for the second opinion (see results). To prevent delay to start of treatment as much as possible, second opinion were always performed within one week after request. Available written reports and digital diagnostic imaging material were either brought by the patient at the visit or send by courier prior to the consultations.

All patients with the (probable) diagnosis lung cancer presenting to the pulmonary oncology outpatient clinic of the VUmc between January 2005 and December 2009, from outside its district and fulfilling the above mentioned second opinion definition were included in this retrospective medical charts study. In total 184 patients were included, of which 4 were referred twice, resulting in a study population of 188 cases. 


\subsection{Study End Points}

\subsubsection{Primary and Secondary Outcomes}

Medical information (e.g. prior therapy, current therapeutic advice) and the patients' and disease characteristics (diagnosis and UICC-6 TNM stage) were collected from the initial evaluation (referral) and the re-evaluation at the specialist centre and compared. Discrepancies in (pathological or clinical) diagnosis, stage of disease and therapeutic advice were noted next to initiator of referral, additional diagnostic tests, trial inclusion and whether therapy was given at the specialist center or elsewhere.

\subsubsection{Secondary End Points}

In the presence of discrepancies, a categorization of their potential impact on patient outcomes (in terms of survival, morbidity and quality of life) was developed based upon evidence based guidelines. (11) Three outcome categories were defined: discrepancies with potential major, minor and identical impact (see Appendix I for a more detailed description of the categories).

\subsection{Statistical Analysis}

Descriptive analyses using chi-square tests to identify possible differences in second opinions were performed using SPSS version 20.0 .

\section{Results}

\subsection{Patients Characteristics}

The majority of patients were male $(57 \%)$ and the mean age at presentation was $59( \pm 10 \mathrm{SD})$ years (see Table 1 for patients and disease characteristics). Males $(n=108)$ were significantly $(\mathrm{p}<0.05)$ older than females $(n=80)$ with a mean age of 61 years versus 56 years respectively.

In $174(93 \%)$ patients a pathological or clinical diagnosis and in $162(86 \%)$ patients the stage was determined, 100 patients had received prior therapy (53\%) and a therapeutic advice had been given to 150 patients $(80 \%)$ at time of presentation. Most patients had an advanced stage (non-) small cell lung cancer.

For 12 patients with a known histopathological diagnosis, no stage was determined at time of referral (staging unknown: $n=3$; definite staging not completed/failed: $n=9$ ). 
Table 1. Study population baseline characteristics $(n=188)$

\begin{tabular}{ll}
\hline & $\mathbf{N}(\%)$ \\
\hline Male & $\mathbf{1 0 8}(\mathbf{5 7 \%})$ \\
Mean Age at presentation & $\mathbf{5 9}( \pm \mathbf{1 0 . 2}$ SD) years
\end{tabular}

Known prior data:

- Diagnosis*

$174(93 \%)$

- Stage

$162(86 \%)$

- Therapy

$233(48 \%)$

- Therapeutic advice

$356(73 \%)$

Histopathological diagnosis lung cancers* $(n=174)$ :

- Non-small cell lung cancer (NSCLC)**

$151(87 \%)$

- Small-cell lung cancer (SCLC)

- Lung cancer other type: carcinoid

- Adenocarcinoma unknown primary

- Mesothelioma

- Large cell carcinoma unknown primary

2 (1\%)

- Squamous cell carcinoma unknown primary

Stage $(\mathrm{n}=162)$ :

- I/IA/IB

$7(4 \%) / 6(3 \%) / 1(1 \%)$

- II/IIA/IIB

$5(3 \%) / 1$ (1\%)/4 (2\%)

- III/IIIA/IIIB

39(22\%)/15(9\%)/24(14\%)

- IV

$95(55 \%)$

- Limited disease

$4(2 \%)$

- Extensive disease

$11(6 \%)$

- Other***

1 (1\%)

-advanced lung cancer ${ }^{\mathfrak{f}}$

$146(78 \%)$

-non-advanced lung cancer

$42(22 \%)$

Legend: *The sub classification by Scagliotti et al., JCO 2008 was not used (Scagliotti et al., 2008) **NSCLC subtypes squamous cell-, large cell-, adenocarcinoma's and nos (non-otherwise specified) together ***Other stage classification for mesothelioma ${ }^{\text {f}}$ Stages 3,4 and extensive disease.

\subsection{Reviews and Additional Diagnostics}

All available imaging material was reviewed next to the tissue of $56(30 \%)$ patients. In 3 patients, the tissue was not of adequate quality for review analysis and in 5 patients it was inconclusive.

Additional histopathological investigations and diagnostics were needed in 127 (68\%) patients, including acquisition of tissue (74, 39\%), EGFR mutation analysis (64, 34\%), PET-/CT-/PET-CT-scans (78, 42\%), and bronchoscopy $(20,11 \%)$. In 61 patients $(33 \%)$ no additional diagnostic procedures nor a review of tissue were considered necessary.

\subsection{Second Opinions Outcomes}

Discrepancies in diagnosis and stage were found in $17(9 \%)$ and in 24 patients $(13 \%)$ respectively. Lung cancer was also de novo diagnosed in 14 patients (7\%) and for 23 patients $(12 \%)$ definite staging was completed (see Table 2).

In the therapy naïve patients $(\mathrm{n}=88)$, a larger number of discrepancies in diagnosis and stage were observed than in patients with prior therapy $(\mathrm{n}=100)$, and more de novo diagnoses and stages were determined $(\mathrm{p}<0.001)$. 
The consequences of discrepancies in diagnosis, stage and therapeutic intent following the second opinions are shown in Table 3. Changes occurred in NSCLC subtype $(n=10)$, lung cancer type $(n=1)$ and from lung cancer to infection $(\mathrm{n}=1)$. All 5 patients presenting with a carcinoma of unknown primary were diagnosed with lung cancer (NSCLC type).

The stage was changed in a higher stage $(\mathrm{n}=10)$, respectively a lower stage $(\mathrm{n}=13)$, when compared to initial staging. One patient switched from SCLC ED to NSCLC stage 4 (classified as other in Table 3) and no staging was determined for the last patient because he had an infection.

The discrepancies in stage had consequences for the therapeutic intent, from palliative therapy to curative therapy $(\mathrm{n}=10)$ and vice versa $(\mathrm{n}=5)$. For 9 patients the therapeutic intent remained the same.

Table 2. Outcomes after second opinion referral

\begin{tabular}{|c|c|c|c|c|}
\hline & $\begin{array}{l}\text { N (\%) Total } \\
(n=188)\end{array}$ & $\begin{array}{l}\text { N (\%) Prior therapy } \\
(n=100)\end{array}$ & $\begin{array}{l}\mathrm{N}(\%) \quad \mathrm{No} \\
\text { therapy }(\mathrm{n}=\mathbf{8 8})\end{array}$ & P-valued \\
\hline \multicolumn{5}{|l|}{ Diagnosis } \\
\hline - Confirmed & $157(84 \%)$ & $92(92 \%)$ & $65(74 \%)$ & $p=0.002$ \\
\hline - Changed & $17(9 \%)$ & $6(6 \%)$ & $11(12 \%)$ & \\
\hline - No prior diagnosis* & $14(7 \%)$ & $2(2 \%)$ & $12(14 \%)$ & \\
\hline \multicolumn{5}{|l|}{$\underline{\text { Stage }}$} \\
\hline \multicolumn{5}{|l|}{ - Confirmed } \\
\hline - Changed & $138(73 \%)$ & $88(88 \%)$ & $50(57 \%)$ & $\mathrm{p}<0.001$ \\
\hline - No prior stage & $24(13 \%)$ & $8(8 \%)$ & $16(18 \%)$ & \\
\hline \multirow{2}{*}{$\begin{array}{l}\text { - Unknown/no stage after } \\
2^{\text {nd }} \text { evaluation** }\end{array}$} & $23(12 \%)$ & $3(3 \%)$ & $20(23 \%)$ & \\
\hline & $3(2 \%)$ & $1(1 \%)$ & $2(2 \%)$ & \\
\hline \multicolumn{5}{|l|}{ Therapeutic advice } \\
\hline - Confirmed & $75(40 \%)$ & $44(44 \%)$ & $31(35 \%)$ & $p=0.452$ \\
\hline - Changed & $70(37 \%)$ & $32(32 \%)$ & $38(43 \%)$ & \\
\hline - No prior advice & $38(20 \%)$ & $21(21 \%)$ & $17(20 \%)$ & \\
\hline - Unknown*** & $5(3 \%)$ & $3(3 \%)$ & $2(2 \%)$ & \\
\hline
\end{tabular}

Legend: a P-value with Pearson chi-square tests *1 patient did not have a pathology based prior diagnosis, this remained unchanged after the second evaluation. Patient has been treated without bypathology confirmed diagnosis. **For 1 patient the diagnosis of recurrent NSCLC was changed to complication of therapy without any sign of recurrence (infection), no stage was therefore assigned. The stage of the other 2 patients was unknown at time of referral and remained unknown after the second evaluation. $* * * 5$ patients only received a diagnostic advice and no therapeutic advice. 
Table 3. Consequences of second opinions on diagnosis, stage and therapeutic intent

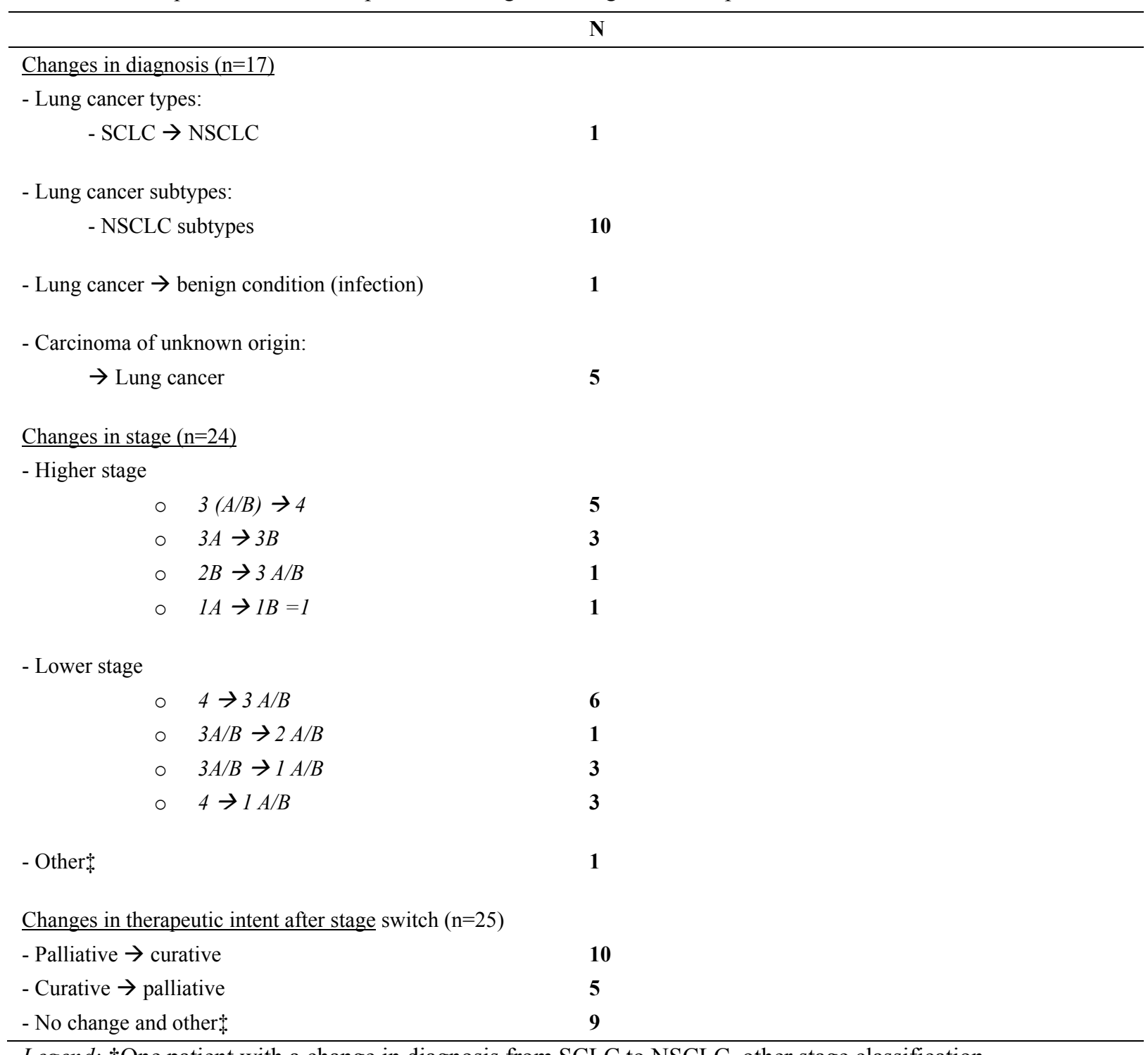

Legend: $\$$ One patient with a change in diagnosis from SCLC to NSCLC, other stage classification.

\subsection{Therapeutic Advice}

The initial therapeutic advice was confirmed in $75(40 \%)$ and changed in 70 patients $(37 \%)$. The other $23 \%$ of the patients received for the first time a therapeutic or a diagnostic advice. The differences observed were not significant (see Table 2).

After the therapeutic advice of the specialist center, approximately one fifth of the patients $(n=42,22 \%)$ were included to receive therapy in a trial setting. Of the total population, $25(13 \%)$ patients came with a request to be treated within a trial. This request was granted in 13. Trial inclusion was significantly higher in the group of patients who requested trial enrollment versus patients who did not $(\mathrm{p}<0.001)$ and in the group with a changed therapeutic advice $(\mathrm{p}<0.001)$. There were no significant differences with regard to trial enrollment when dividing the population according to prior therapy.

Most patients were treated at the specialist center (128 patients, 68\%), 56 patients were referred back to their hospital. Of the remaining patients, 2 died before therapy initiation and 2 were discharged.

\subsection{Discrepancies with Potential Consequences on Patient Outcomes}

In total, 91 discrepancies were found after the second opinion, including changes in diagnosis, stage and therapeutic advice and were classified according to their potential impact on patient outcomes (minor, major and 
identical, see Appendix I). When multiple discrepancies were found in 1 patient, only the discrepancy with the most important potential impact was counted.

For 53 patients ( $28 \%$ of the total population and $58 \%$ of the group of patients with changes), the discrepancies had a potential major impact on patient outcomes, for 20 patients $(22 \%)$ a potential minor impact and for 18 patients $(20 \%)$ a potential identical impact. There were no significant differences in the number of discrepancies with potential major consequences between the group with a changed and unchanged therapeutic advice. The most frequent discrepancies with potential major consequences $(n=53)$ concerned (in descending order of frequencies) a modification in diagnosis or stage $(n=24)$, chemotherapy $(n=10)$, mutation analysis $(n=7)$, the resectability of a tumour $(n=4)$, neo- or adjuvant modalities to surgery $(n=3)$ and the switch from concurrent chemoradiation to chemotherapy ( $\mathrm{n}=3$ ) (see Table 4$)$.

Table 4. Nature of changes with potential major consequences $(\mathrm{n}=53)$

\begin{tabular}{ll}
\hline & N(\%) \\
\hline Diagnosis and/or staging modification & $\mathbf{2 4}(\mathbf{4 5 \%})$ \\
Decision to give chemotherapy or not & $\mathbf{1 0}(\mathbf{1 9 \% )}$ \\
Performing mutation analysis* & $\mathbf{7 ( 1 3 \% )}$ \\
Tumour resectability & $\mathbf{4 ( 7 \% )}$ \\
Adding neo/adjuvant modalities to surgery & $\mathbf{3 ( 6 \% )}$ \\
Switch from chemotherapy to concurrent chemoradiation (and eventually surgery) and vice versa & $\mathbf{3 ( 6 \% )}$ \\
Switch from radiotherapy to chemoradiation and vice versa & $\mathbf{1 ( 2 \% )}$ \\
Switch from radiotherapy to surgery & $\mathbf{1 ( 2 \% )}$ \\
\hline
\end{tabular}

Legend: *Mutation analysis on K-ras en EGFR-mutations.

The general outcomes of second opinions for the patients with advanced lung cancer (as a subgroup of the total study population) are shown in Table 5 (more detailed data available on request).

Table 5. Second opinion outcomes of patients with advanced* lung cancer $(\mathrm{n}=146)$

\begin{tabular}{|c|c|}
\hline & $\mathbf{N}(\%)$ \\
\hline \multicolumn{2}{|l|}{ Changes after the second opinion } \\
\hline -in diagnosis & $9(6 \%)$ \\
\hline - $\quad$ NSCLC subtype & 8 \\
\hline - $\quad \mathrm{SCLC} \rightarrow \mathrm{NSCLC}$ & 1 \\
\hline -in stage & $22(15 \%)$ \\
\hline - $\quad$ Lower stage & 13 \\
\hline - $\quad$ Higher stage & 8 \\
\hline - $\quad \mathrm{ED}^{* *} \rightarrow 4$ & 1 \\
\hline -in therapeutic advice & $59(40 \%)$ \\
\hline Number of changes with potential consequences on patient outcomes & $75(51 \%)$ \\
\hline Number of changes with potential major consequences on patient outcomes*** & $39(27 \%)$ \\
\hline \multicolumn{2}{|c|}{$\begin{array}{l}\text { Legend: *Stages } 3,4 \text { and extensive disease } * * \text { From ED (extensive disease) to stage } 4 * * * \text { The most frequent } \\
\text { changes with major potential impact on patient outcomes were (in descending order) a modification in diagnosis } \\
\text { or stage, chemotherapy, mutation analysis, switch from concurrent chemoradiation to chemotherapy and the } \\
\text { resectability of a tumour. }\end{array}$} \\
\hline
\end{tabular}




\section{Discussion}

Second opinions have proven to be of value for a number of different diseases, especially in oncology (Briggs, Flynn, Worthington, Rennie, \& McKinstry, 2008; Kronz, Westra, \& Epstein, 1999; Lueck, Jensen, Cohen, \& Weydert, 2009; Manion, Cohen, \& Weydert, 2008). The percentages of discrepancies after a second opinion vary between $1 \%$ and $60 \%$, depending on the disease and anatomic site, the nature and quality of pathological specimen (cytology or histopathology), the applied definition criteria for the changes (in diagnosis, stage or therapeutic advice), their clinical impact on therapy and/or prognosis and the patient population (Tattersall et al., 2009; Briggs et al., 2008; Kronz et al., 1999; Lueck et al., 2009; Manion et al., 2008; Frable, 2006; Kronz \& Westra, 2005; Zembowicz, Ahmad, \& Lyle, 2011).

Present study provides the very first report of patient initiated second opinions for lung cancer in a specialist centre, which resulted in a substantial number of significant discrepancies in diagnosis, stage and therapeutic advice after the re-evaluation of patients' data. It shows that a patient initiated second opinion in a specialist centre might have impact on the treatment (outcomes) of individual patients and is therefore -in this study especially with regard to the group of advanced lung cancer- of value.

Second opinions solely on lung cancer have never been investigated and in other reports with $\mathrm{mixed} /$ miscellaneous patient populations, the number of lung cancer cases was too limited to draw specific conclusions in this group (Maaskant et al., 2009; Lueck et al., 2009; Manion et al., 2008; Mellink et al., 1999; Tsung, 2004). Although it is difficult to compare present results with general second opinion data, it is striking that our percentages discrepancies and their potential impact on patient outcomes are higher than reported in literature. In addition, it is even more striking that our findings show such large percentages of discrepancies as they are the result of patient initiated second opinions. One would tend to think that, as patients refer themselves regardless of the probability to find a discrepancy, only a minor number of discrepancies would be found. Our findings demonstrate otherwise. There may be several explanations for our observations.

First of all, there might be a "pre-selection" of patients since younger females (compared to the lung cancer population) are slightly overrepresented in our study sample. They are in general more inclined to request a second opinion (Mellink et al., 2003; Tattersall et al., 2009; Gommer, Poos, \& Burgers, 2010; Mellink et al., 2006) and consequently, might be more inclined to urge their treating physicians to perform more additional diagnostic procedures and try more experimental and/or aggressive treatments. Still, this does not explain all findings, as the patients of this study received advice in accordance with current international guidelines (IKC, 2011). Additionally, our study population seems representative since the geographical spread is rather homogenous and patients came from all over the country.

Second, the definitions we applied for a second opinion and a discrepancy are not identical to other authors'. Although some elements are similar, (Manion et al., 2008; Tsung et al., 2004; Mellink et al., 2006) e.g. a change from benign to malignant or in stage; differences remain, such as the distinction between a potential major or minor impact (which may also be subject to change and personal preferences), lung cancer specific elements and the second opinion type (patient initiated) (Westra, Kronz, \& Eisele, 2002). The classification we used is nevertheless in accordance with evidence based literature (see appendix) (IKC, 2011) and we have attempted to make the most complete definition of a (patient initiated) second opinion, consistent with our daily practice.

Third, distinguishing malignancies from benign disease in the lung and the pleura is laborious and may have led to evaluation differences between different pathologists (Churg et al., 2000; Churg et al., 2011). Specimen type (cytology versus histopathology) and inter- and intrarater variability play herein a role (Frable et al., 2006; Kronz et al., 2005).

Important to note is the that second opinions were performed in a specialist centre for thoracic oncology, where a team of trained and experienced specialists work, and diagnostic facilities, most up to date treatment options and possibilities for trial enrolment are present. Patients there were discussed in a specialized thoracic oncology MDT as well drawing conclusions was much more a team based advice, rather than a single specialist's opinion (Briggs et al., 2008; Kronz et al., 2005; Cooper \& Fitzgibbons, 2002; Staradub, Messenger, Hao, Wiley \& Morrow, 2002; Zan, Yousem, Carone \& Lewin, 2010). Training promotes earlier recognition of symptoms and disease (Staradub et al., 2002), and the second reviewer (e.g. pathologist) usually has more information than the referring physician (Westra et al., 2002). Next to this, it is known that more discrepancies are found when patients are being referred from regional hospitals to academic centers (Kronz et al., 2005; Tsung et al., 2004). The specialist approach resulted in the refinement of diagnosis and stage, the administration of "tailored" therapy and thus the increase of discrepancies between first and second opinions.

This specialist approach is also reflected in the rather high number of additional diagnostic tests despite the 
availability of these tests and presence of material from referring hospitals and the fact that patients also had been discussed in MDT's there. This is probably due to several reasons. First, the second opinions were the patients' wish, regardless of the capacities, quality or availability of investigations already present in the referring hospitals. As some patients referred themselves before the definitive diagnosis, additional diagnostic tests were necessary. Next to this, it is very probable to think that when patients request a second opinion, they wish to have a as complete as possible diagnosis, including diverse diagnostic investigations. This needs to be in agreement with the "new" treating physician, naturally. Moreover, review of imaging and material was not always sufficient or adequate for staging, and some diagnostic procedures had failed at the referring hospitals. Additional investigations were therefore legitimate. Last, specific investigations more feasible at the specialist centre (EBUS/EBUS mediated procedures, TBNA, mediastinal sampling, mutation analysis, etc.) were required.

Based on the foregoing, it is probable that the large number of discrepancies we report are rather the result of the specialist approach than the patients' intuition. Nevertheless, our results show that patient initiated second opinions are meaningful and may be beneficial for patients in term of outcomes, even for patients with advanced cancer. It is therefore important to acknowledge and discuss the patients' feelings and perspective in case of a wish for a second opinion. Furthermore, taking the patient's request seriously often results in a beneficial/advantageous situation for both patient and physician (Moumjid et al., 2007; Maaskant et al., 2009; van Gijn \& van de Velde, 2010; Axon, Hassan, Niv, Beglinger \& Rokkas, 2008).

A potential risk of a second opinion is delay in consultation, additional diagnostic tests and subsequently delay in start of therapy. Therefore, it is necessary for those who perform second opinions to make the threshold as low as possible and reduce the waiting time before consultation, as well as for additional diagnostic tests, to a minimum. This implies that facilities in the hospital of the second opinion should be sufficient to cope with this type of extra demands added to providing regular care, as it was the case in the present study. If this is impossible, physicians and hospitals should be very restrictive in performing a second opinion and patients asking a second opinion should be informed about this without any delay.

\subsection{Limitations}

A possible limitation lies within our study design. The study is retrospective, requiring interpretations from the reviewers of the data (Maaskant et al., 2009). In case of disagreement, consultation between the authors took place until complete agreement was reached.

Furthermore, some data were not retrievable. This is the case for follow-up data on the outcome of the advice after sending back patients to referring hospitals $(\mathrm{n}=56)$. However, the advice was followed in most cases, which might indicate the trust of the patient and consequently the "referred back" physician in the given advice. Also due to the study design, it was impossible to measure any effect on survival or quality of life reflecting the value of the given advice.

The generalization of our data results may also pose a problem since the Dutch health care system differs from other countries. There are however many similar elements in the treatment trajectory and therapy since the Dutch treatment guidelines are based upon internal guidelines and literature (IKC, 2011).

\subsection{Further Implications}

The discussion on health care concentration and quality of care extends beyond any border (Curry et al., 2011; Gooiker et al., 2010; Luchtenborg et al., 2013; van Gijn \& van de Velde, 2010; van Gijn et al., 2010). Present study results seem to contribute to this discussion as being in its favour, but this subject goes beyond the scope of this study. Further research on physician initiated referrals are needed to compare with the patients' and gain more insight into physicians' second opinion referral patterns to tertiary centers.

We did not investigate the financial impact of second opinions either, as we were solely interested in the medical comparison of the first with the second opinion. The cost effectiveness of second opinions is conceivable, though (DiPiro et al., 2002; Epstein et al., 1996; Wurzer et al., 1998). Is it difficult to generalize on the financial impact of second opinions based on our results, as there are several effects which might result in extra costs as well. Extra inevitable costs are those of consultation, review by pathologist and additional investigations in case of outdated or inconclusive initial tests. However for the latter, it is already questionable if additional investigations result in (more) evidence for therapy. In general, any improvement of therapy based on evidence should not be considered as extra costs. It should rather be considered as a saving, even if the prescribed drugs are much more expensive, for instance TKIs (gefitinib, erlotinib) versus standard chemotherapy, as the patient receives more tailored therapy and unnecessary treatment options are being prevented. The newest web-based communication facilities such as teleconference might help reducing the costs, barriers and risks (such as delay in starting 
treatment) to second opinion consultations, limit their numbers and unburden centres (Zembowicz et al., 2011). Although we did not score the importance of the interviews and physical examination for the advice of the specialist centre, a consultation by means of teleconference could have been enough for 61 (32.5\%) patients in our study sample, as no additional diagnostics or examination were performed.

Next to the possible financial advantages and probable potential impact on patient outcomes, various researches have shown that patients are not only more self-confident but that they also have more confidence in their physician and therapy after a second opinion. They are more satisfied and understand their situation and illness better (Mellink et al., 2003; Tattersall et al., 2009; Axon et al., 2008).

Provided that the necessary health care facilities are available, we think second opinions should be incorporated in the guidelines for lung cancer like in the United Kingdom (http:/guidance.nice.org.uk/QS17) and obtained before initiation of the first therapy as changes may have important consequences for the patient and the patient-physician relationship (Smith, 2011; Scagliotti et al., 2008). The most important should be that colleagues feel comfortable about going in discussion with their patients about seeking a second opinion if the patient wishes to, and take this (well-considered) step together in order to put the quality of patient care at first.

\section{Conclusions}

Second opinions may lead to significant discrepancies in diagnosis and therapeutic advice in a substantial number of lung cancer patients and should therefore be an integral part of quality practice.

\section{Acknowledgements}

The authors thank J. Vincenten for his cooperation and his data on mutation analysis and S. Cornielje-Hamersma and J. Wilhelmus for their help with their data on PET-CT scans.

\section{Prior Presentation of Data}

A part of the contents of this manuscript (preliminary data analyses) has been presented at the World Conference on Lung Cancer in Amsterdam, the Netherlands, in July 2011.

Competing Interests Statement

All authors state that they have no conflicts of interest.

\section{References}

Axon, A., Hassan, M., Niv, Y., Beglinger, C., \& Rokkas, T. (2007). Ethical and legal implications in seeking and providing a second medical opinion. Digestive Diseases, 26(1), 11-17. http://dx.doi.org/10.1159/000109379

Briggs, G. M., Flynn, P. A., Worthington, M., Rennie, I., \& McKinstry, C. S. (2008). The role of specialist neuroradiology second opinion reporting: is there added value?. Clinical radiology, 63(7), 791-795. http://dx.doi.org/10.1016/j.crad.2007.12.002

Churg, A., Cagle, P., Colby, T. V., Corson, J. M., Gibbs, A. R., Hammar, S., ... \& Wick, M. (2011). The fake fat phenomenon in organizing pleuritis: A source of confusion with desmoplastic malignant mesotheliomas. The American journal of surgical pathology, 35(12), 1823-1829. http://dx.doi.org/10.1097/ PAS.0b013e31822a2481

Churg, A., Colby, T. V., Cagle, P., Corson, J., Gibbs, A. R., Gilks, B., .. \& Travis, W. D. (2000). The separation of benign and malignant mesothelial proliferations. American Journal of Surgical Pathology, 24(9), 1183-1200. http://dx.doi.org/10.1097/00000478-200009000-00001

Cooper, K., \& Fitzgibbons, P. L. (2002). Institutional consultations in surgical pathology: How should diagnostic disagreements be handled?. Archives of pathology \& laboratory medicine, 126(6), 650-651.

Curry, L. A., Spatz, E., Cherlin, E., Thompson, J. W., Berg, D., Ting, H. H., ... Bradley, E. H. (2011). What distinguishes top-performing hospitals in acute myocardial infarction mortality rates? A qualitative study. Annals of Internal Medicine, 154(6), 384-390. http://dx.doi.org/10.7326/0003-4819154-6-201103150-00003

DiPiro, P. J., van Sonnenberg, E., Tumeh, S. S., \& Ros, P. R. (2002). Volume and impact of second-opinion consultations by radiologists at a tertiary care cancer center: data. Academic radiology, 9(12), 1430-1433. http://dx.doi.org/10.1016/S1076-6332(03)80671-2

Ellis, J. (2012). The impact of lung cancer on patients and carers. Chronic respiratory disease, 9(1), 39-47. http://dx.doi.org/10.1177/1479972311433577

Epstein, J. I., Walsh, P. C., \& Sanfilippo, F. (1996). Clinical and cost impact of second-opinion pathology: review 
of prostate biopsies prior to radical prostatectomy. The American journal of surgical pathology, 20(7), 851-857. http://dx.doi.org/10.1097/00000478-199607000-00008

Frable, W. J. (2006). Surgical pathology-second reviews, institutional reviews, audits, and correlations: what's out there? Error or diagnostic variation?. Archives of pathology \& laboratory medicine, 130(5), 620-625.

Gommer, AMR, Poos, MJJCR, \& Burgers, JAN. (2010). Longkanker. Omvang van het probleem. Hoe vaak komt longkanker voor en hoeveel mensen sterven eraan? In Volksgezondheid Toekomst Verkenning, Nationaal Kompas Volksgezondheid. Retrieved from http:// www.nationaakompas.nl

Gooiker, G. A., Van Gijn, W., Post, P. N., van de Velde, C. J. H., Tollenaar, R. A. E. M., \& Wouters, M. W. J. M. (2010). A systematic review and meta-analysis of the volume-outcome relationship in the surgical treatment of breast cancer. Are breast cancer patients better of with a high volume provider?. European Journal of Surgical Oncology (EJSO), 36, S27-S35. http://dx.doi.org/10.1016/j.ejso.2010.06.024

Hewitt, M., Breen, N., \& Devesa, S. (1999). Cancer prevalence and survivorship issues: analyses of the 1992 National Health Interview Survey. Journal of the National Cancer Institute, 91(17), 1480-1486. http://dx.doi.org/10.1093/jnci/91.17.1480

IKC (Integraal Kankercentrum Nederland)-Oncoline. (2011). Richtlijn oncologische zorg-Richtlijn Kleincellig Longcarcinoom en Niet-kleincellig carcinoom. Oncoline Integraal Kankercentrum Nederland 2011. Retrieved from http://www.oncoline.nl/kleincellig-longcarcinoom; http://www.oncoline.nl/niet-kleincellig -longcarcinoom

Kronz, J. D., \& Westra, W. H. (2005). The role of second opinion pathology in the management of lesions of the head and neck. Current opinion in otolaryngology \& head and neck surgery, 13(2), 81-84. http://dx.doi.org/10.1097/01.moo.0000156162.20789.66

Kronz, J. D., Westra, W. H., \& Epstein, J. I. (1999). Mandatory second opinion surgical pathology at a large referral hospital. Cancer, 86(11), 2426-2435. http://dx.doi.org/10.1002/(SICI)1097-0142(19991201)86:11 $<2426::$ AID-CNCR34>3.0.CO;2-3

Lüchtenborg, M., Riaz, S. P., Coupland, V. H., Lim, E., Jakobsen, E., Krasnik, M., ... \& Møller, H. (2013). High procedure volume is strongly associated with improved survival after lung cancer surgery. Journal of Clinical Oncology, 31(25), 3141-3146. http://dx.doi.org/10.1200/JCO.2013.49.0219

Lueck, N., Jensen, C., Cohen, M. B., \& Weydert, J. A. (2009). Mandatory second opinion in cytopathology. Cancer Cytopathology, 117(2), 82-91.

Maaskant, J. M., \& van Muilekom, H. A. M. (2009). Eerste arts zit er zelden naast-Patienten met kanker die een second opinion aanvragen, zijn vooral op zoek naar meer informatie, hoop en geruststelling. Slechts in een enkel geval leidt het bezoek aan een andere arts tot een andere diagnose. Ergo, verbeter de voorlichting aan patienten en zij zullen minder vaak een tweede oordeel aanvragen. Medisch Contact, 64(14), 605.

Manion, E., Cohen, M. B., \& Weydert, J. (2008). Mandatory second opinion in surgical pathology referral material: clinical consequences of major disagreements. The American journal of surgical pathology, 32(5), 732-737. http://dx.doi.org/10.1097/PAS.0b013e31815a04f5

Mellink, W. A., Henzen-Logmans, S. C., Bongaerts, A. H., Pruyn, J. F., van Geel, A. N., \& Wiggers, T. (1999). Second Opinion Consult Clinic for Surgical Oncology in the Daniel den Hoed Clinic: analysis of the first 245 patients. Ned Tijdschr Geneeskd, 143(49), 2471-2475.

Mellink, W. A. M., Dulmen, A. M. V., Wiggers, T., Spreeuwenberg, P. M. M., Eggermont, A. M. M., \& Bensing, J. M. (2003). Cancer patients seeking a second surgical opinion: results of a study on motives, needs, and expectations. Journal of clinical oncology, 21(8), 1492-1497. http://dx.doi.org/10.1200/JCO.2003.12.058

Mellink, W. A. M., Henzen-Logmans, S. C., Bongaerts, A. H. H., Ooijen, B. V., Rodenburg, C. J., \& Wiggers, T. H. (2006). Discrepancy between second and first opinion in surgical oncological patients. European Journal of Surgical Oncology (EJSO), 32(1), 108-112. http://dx.doi.org/10.1016/j.ejso.2005.08.007

Moumjid, N., Gafni, A., Bremond, A., \& Carrere, M. O. (2007). Seeking a second opinion: Do patients need a second opinion when practice guidelines exist?. Health Policy, 80(1), 43-50. http://dx.doi.org/10.1016/j.healthpol.2006.02.009

Postmus, P. E. (1998). Second opinion geregeld? Ongewilde negatieve effecten. Medisch Contact, 53(3), 82.

Scagliotti, G. V., Parikh, P., von Pawel, J., Biesma, B., Vansteenkiste, J., Manegold, C., ... \& Gandara, D. (2008). Phase III study comparing cisplatin plus gemcitabine with cisplatin plus pemetrexed in chemotherapy-naive 
patients with advanced-stage non-small-cell lung cancer. Journal of Clinical Oncology, 26(21), 3543-3551. http://dx.doi.org/10.1200/JCO.2007.15.0375

Smith, L. B. (2011). Pathology review of outside material: When does it help and when can it hurt?. Journal of Clinical Oncology, 29(19), 2724-2727. http://dx.doi.org/10.1200/JCO.2011.34.7906

Staradub, V. L., Messenger, K. A., Hao, N., Wiely, E. L., \& Morrow, M. (2002). Changes in breast cancer therapy because of pathology second opinions. Annals of surgical oncology, 9(10), 982-987.

Tattersall, M. H., Dear, R. F., Jansen, J., Shepherd, H. L., Devine, R. J., Horvath, L. G., \& Boyer, M. J. (2009). Second opinions in oncology: the experiences of patients attending the Sydney Cancer Centre. Med J Aust, 191(4), 209-212.

Tsung, J. S. (2004). Institutional pathology consultation. The American journal of surgical pathology, 28(3), 399-402. http://dx.doi.org/10.1097/00000478-200403000-00015

Van Gijn, W., \& van de Velde, C. J. H. (2010). Improving quality of cancer care through surgical audit. European Journal of Surgical Oncology (EJSO), 36, S23-S26. http://dx.doi.org/10.1016/j.ejso.2010.06.026

Van Gijn, W., Gooiker, G. A., Wouters, M. W. J. M., Post, P. N., Tollenaar, R. A. E. M., \& van de Velde, C. J. H. (2010). Volume and outcome in colorectal cancer surgery. European Journal of Surgical Oncology (EJSO), 36, S55-S63. http://dx.doi.org/10.1016/j.ejso.2010.06.027

Westra, W. H., Kronz, J. D., \& Eisele, D. W. (2002). The impact of second opinion surgical pathology on the practice of head and neck surgery: a decade experience at a large referral hospital. Head \& neck, 24(7), 684-693. http://dx.doi.org/10.1002/hed.10105

Wurzer, J. C., Al - Saleem, T. I., Hanlon, A. L., Freedman, G M., Patchefsky, A., \& Hanks, G E. (1998). Histopathologic review of prostate biopsies from patients referred to a comprehensive cancer center. Cancer, 83(4), 753-759. http://dx.doi.org/10.1002/(SICI)1097-0142(19980815)83:4<753::AID-CNCR18>3.0.CO;2-R

Z Zan, E., Yousem, D. M., Carone, M., \& Lewin, J. S. (2010). Second-Opinion Consultations in Neuroradiology 1. Radiology, 255(1), 135-141. http://dx.doi.org/10.1148/radiol.09090831

Zembowicz, A., Ahmad, A., \& Lyle, S. R. (2011). A comprehensive analysis of a web-based dermatopathology second opinion consultation practice. Archives of pathology \& laboratory medicine, 135(3), 379-383. 


\section{Appendix I}

Classification of discrepancies in diagnosis, stage and therapeutic advice after a second opinion and description of these discrepancies according to their potential major, minor and identical impact on patient outcomes.

\section{Classification of criteria for Non-Small Cell Lung Cancer (NSCLC) (IKC)}

\section{General rules:}

-If a patient fulfils the criteria of both changes with potential minor and major impact on patient outcome, the major change should count above the minor change

-If a patient fulfils the criteria of a change with potential major impact, then it doesn't matter whether a patient is included in a trial, the fact that a patient fulfils the criteria of a change with major impact counts above trial inclusion

-If a patient doesn't fulfil the criteria of a change with major impact and becomes included in a trial, then the patient's outcome should be regarded as identical, and categorized according criteria 1 of the changes with identical impact on patient outcome.

-When multiple discrepancies are found in 1 patient, only the discrepancy with the most important potential impact is counted

\section{Changes with potential major impact (aimed at improvement of outcome by changed therapy)}

1. inoperable $\leftarrow \rightarrow$ operable

a. surgery $\leftrightarrow$ palliative chemotherapy/chemotherapy + sequential radiotherapy (RT)/expectative management/concurrent chemoradiation with curative intent

b. no surgical resection after therapy induction

c. inoperable (as a result of bad condition/Body Mass Index/Lung Function/high risk operation (e.g. in necrotic area)

2. palliative RT $\leftarrow \rightarrow$ RT with curative intent

3. chemotherapy $\leftarrow \rightarrow$ concurrent chemoradiation (and eventually resection)

4. treatment of brain metastases

a. whole brain RT $\leftrightarrow$ stereotactic RT (SRT)

b. surgical metastasectomy $\leftarrow \rightarrow$ SRT

c. whole brain RT $\leftrightarrow \rightarrow$ surgical metastasectomy

5. performing mutation analysis and its results :

a. in case of positive EGFR mutation $(+) \rightarrow$ change with potential major impact

i. EGFR + exon $19 \rightarrow$ change with potential major impact

ii. EGFR + exon $21 \rightarrow$ change with potential major impact

iii. EGFR + exon 20 (resistance to Tyrosine Kinase Inhibitors (TKI) $\rightarrow$ change with potential identical impact

iv. EGFR analysis later during treatment trajectory $\rightarrow$ does not count as a potential change

b. in case of negative EGFR mutation $(-)$ and positive K-ras mutation $(+) \rightarrow$ check for other changes with potential impact and classify as a change with potential minor or identical impact

c. in case of EGFR mutation - and K-ras + and trial inclusion $\rightarrow$ change with potential identical impact

6. no chemotherapy $\leftarrow \rightarrow$ chemotherapy

a. also valid for: no biological $\leftarrow \rightarrow$ biological (in case of registered biologicals)

7. prognostic staging

a. based on clinical/pathological judgement and review that the diagnosis malignant should be changed in benign and vice versa

b. based on clinical/pathological judgement and review that the diagnosis lung cancer should be 
changed in an other cancer type

c. based on clinical/pathological judgement and review that the carcinoma of unknown origin/diagnosis should be changed in lung cancer

d. based on clinical/imaging judgement and review that stages $(1 \leftarrow \rightarrow 2 \leftarrow \rightarrow 3 \leftarrow \rightarrow 4)$ should be changed

e. based on clinical/pathological judgement and review that the diagnosis lung cancer type should be changed in another lung cancer type and vice versa

i. $\mathrm{SCLC} \leftarrow \rightarrow$ NSCLC

ii. $\quad$ SCLC/NSCLC $\leftrightarrow \rightarrow$ trachea tumour

f. based on clinical/imaging judgement and review that within stage 4 , the type of metastases should be changed:

i. in case of known metastases, a new localization of metastases is determined or rejected

8. change in extent of surgery

a. lobectomy $\leftarrow \rightarrow$ wedge excision

b. lobectomy $\leftrightarrow \rightarrow$ more extensive resection

9. RT with curative intent $\leftarrow \rightarrow$ chemoradiation with curative intent

10. surgical resection $\leftarrow \rightarrow$ resection with additional treatment modalities

a. $\quad$ resection $\leftrightarrow \rightarrow$ resection + neoadjuvant chemotherapy

b. resection $\leftarrow \rightarrow$ resection + neoadjuvant concurrent chemoradiation

c. resection $\leftarrow \rightarrow$ resection + adjuvant chemotherapy

d. switch in the number of additonal treatment modalities

11. RT with curative intent $\leftarrow \rightarrow$ surgery

12. surgery $\leftarrow \rightarrow$ endobronchial therapy

13. endobronchial therapy $\leftarrow \rightarrow$ endobronchial therapy + additional treatment modalities

\section{Changes with potential minor impact}

1) minor changes aimed at improvement of care/quality of life

a. no palliative RT (no therapy) $\leftrightarrow \rightarrow$ palliative RT

b. palliative RT $\leftrightarrow \rightarrow$ palliative chemotherapy/biological (without a EGFR mutation)

c. no therapy/expectative management/supportive care therapy instead of suggested therapy (in case of stage 4/advanced disease with prior therapy with a number of chemotherapy lines whereby therapy has no impact anymore on survival, but exclusively on quality of life)

d. therapy switch within a palliative setting

e. switch of chemotherapy to biological and vice versa (in case of EGFR - and K-ras + or -mutation)

2) addition or removal of a treatment modality within a treatment with the same intent or a palliative/supportive treatment setting

a. palliative chemotherapy+ sequential RT $\leftarrow \rightarrow$ palliative chemotherapy

b. palliative RT + palliative chemotherapy $\leftarrow \rightarrow$ palliative RT

c. palliative. $\mathrm{RT}+$ palliative chemotherapy $\leftarrow \rightarrow$ palliative chemotherapy

d. $\quad$ SRT $\leftrightarrow$ neoadjuvant chemotherapy + SRT

e. addition of endobronchial therapy to chemotherapy within a palliative treatment setting

3) prognostic staging

a. based on clinical/pathological judgement and review that the diagnosis of NSCLC subtype (adenocarcinoma/squamous cell/large cell/not otherwise specified) should be changed in 
another subtype

b. based on clinical/pathological judgement and review that the diagnosis of a lung cancer type (NSCLC/carcinoid/ unknown lung cancer type) should be changed in another lung cancer type

c. based on clinical/pathological judgement and review that the diagnosis of carcinoid subtype (typical/atypical) should be changed in another subtype

d. based on clinical/imaging judgement and review that stages specifications (of stage $1 / 2 / 3$ ) within the same stage should be changed $(\mathrm{A} \leftarrow \rightarrow \mathrm{B})$

4) change in chemotherapy regimen

a. gemcitabine/cisplatin $\rightarrow$ gemcitabine/carboplatin

5) change in the sequence of treatment modalities

a. neoadjuvant chemotherapy + surgery $\longleftrightarrow$ surgery + adjuvant chemotherapy

6) the wish/request to be treated with chemotherapy within a trial is not granted

\section{Changes with potential identical impact}

1. change in therapy resulting in trial inclusion in the absence of a change with potential major impact

a. any kind of trial

b. trials with biologicals (provided that the EGFR mutation is negative)

NB: if there is already the suggestion that a patient could be enrolled in a trial and this suggestion is being granted, this does not count as a potential change.

2. the patient refuses the therapeutic advice of the expert center, is referred back to the referring hospital and receives therapy according to the first advice he received before referral

3. switch of unknown therapy to therapy

4. EGFR mutation of exon $20=$ TKI resistance

\section{Classification of criteria for Small Cell Lung Cancer (SCLC) (IKC)}

\section{Changes with potential major impact (aimed at improvement of outcome by changed therapy)}

1. addition of prophylactic cranial irradiation for SCLC with extensive disease

2. surgical resection of a residual tumour

3. expectative management/no chemotherapy $\leftarrow \rightarrow$ chemotherapy

i. after surgery

ii. in case of recurrence/no recurrence and chance of cure

\section{Changes with potential minor impact}

1. expectative management/no chemotherapy $\leftarrow \rightarrow$ chemotherapy

a. in case there is no chance of cure anymore

\section{Copyrights}

Copyright for this article is retained by the author(s), with first publication rights granted to the journal.

This is an open-access article distributed under the terms and conditions of the Creative Commons Attribution license (http://creativecommons.org/licenses/by/3.0/). 